Index Copernicus Value: 83.27 ISSN (e)-2347-176x ISSN (p) 2455-0450 crossref DOI: https://dx.doi.org/10.18535/jmscr/v5i1.87

\author{
Journal Of Medical Science And Clinical Research \\ IGM Publication \\ An official Publication of IGM Publication
}

\title{
Effect of Caffeine on Cardiorespiratory Parameters in Sedentary, Healthy Young Male Adults
}

\author{
Authors
}

\author{
Dr Nazish Shaikh ${ }^{1}$, Dr Sonali Pande ${ }^{2}$, Dr Arun Chutani ${ }^{3}$ \\ ${ }^{1}$ Assistant Medical Officer, EPI, Mumbai. \\ Email:drnazish1984@gmail.com \\ ${ }^{2}$ Associate Professor, Dept of Physiology, TNMC, Mumbai \\ ${ }^{3}$ Senior Registrar, Dept of Physiology, TNMC, Mumbai.
}

Email: docarun26@gmail.com

Corresponding Author

Dr Sonali S. Pande

Associate Professor, Dept of Physiology, TNMC \&BYL Nair Ch Hospital, Mumbai Central, Mumbai-08 Email: drsonalipande@gmail.com, Mobileno: 9820904373

\begin{abstract}
Background: In current days of highly competitive life, all of us are under pressure to perform better. Once we reach optimal level of performance according to genetic makeup, the subsequent increment in performance depends upon various ergogenic methods to enhance the energy delivery system. Of the various ergogenic methods available to achieve excellence, caffeine consumption is increasingly popular.
\end{abstract}

Aims and Objectives: The present study was undertaken to study the effect of caffeine (6mg/kg body weight) on cardiovascular \& respiratory parameters after 5 minutes of stationary cycling on a bicycle ergometer, in sedentary young male adults of age 18-26 years.

Materials and Methods: The participants were made to complete a graded exercise protocol on a bicycle Ergometer in order to determine the power output required to elicit a THR, equating to 55\% of individual age predicted maximum HR (220 - age). The following parameters were measured, Systolic BP (SBP) in mm Hg, Diastolic BP $(D B P)$ in $\mathrm{mm} \mathrm{Hg}$, Mean Arterial Pressure (MAP) in mm Hg, Maximum heart rate in beats per minute (bpm), Target heart rate (THR) in beats per minute (bpm), Double product of HR \& SBP, Respiratory rate (RR) per minute, Maximum volume of oxygen consumption by body in each minute during exercise (VO2max) in $\mathrm{ml} / \mathrm{kg} / \mathrm{min}$. At the end of 5 minutes (i.e. during recovery period), subjects pulse rate was measured at three different times: at the end of 1 minute, 3 minutes , 5 minutes after the exercise was over. In the second visit after 2 days of first session the same participants were given caffeine anhydrous powder in a dose of $6 \mathrm{mg} / \mathrm{kg}$ of body weight, one hour prior to exercise session and after 5 minutes of exercise session, the above mentioned parameters were measured. All the mentioned parameters before and after caffeine consumption were compared using Paired t- test.

Results: There was statistically significant increase in systolic blood pressure, diastolic blood pressure, mean arterial pressure, target heart rate, double product of heart rate and systolic blood pressure, in respiratory rate, 1 minute post-exercise heart rate (PHR1),3 minute post-exercise heart rate (PHR3), 5 minute post-exercise heart rate (PHR5) and significant decrease in VO2max, after one hour of caffeine consumption with exercise in male and female participants.

Conclusion: The present study shows that caffeine ( $6 \mathrm{mg} / \mathrm{kg}$ body weight) ingestion prior to a short term exercise has an ergogenic effect by making appropriate changes in above mentioned cardiovascular \& respiratory parameters in a normal young adults of age 18-26 years.

Keywords-caffeine, submaximal exercise, cardiopulmonary parameters, VO2max. 


\section{Introduction}

Exercises are usually performed to improve cardiorespiratory \& muscular endurance. ${ }^{1}$ Submaximal testing is a popular \& effective way of evaluating cardiorespiratory fitness (CRF) \& is valuable in developing individualized exercise programmes, ${ }^{2}$ as test administrators requires less training and exercise intensity is realistic for most participants. Cycle ergometer has an appealing mode of testing CRF as it allows the selection of precise work rates that can be expressed with appropriate units of power, and is usually well tolerated by individuals with orthopaedic and other physical limitation and also heart rate, blood pressure \& electrographic data can be easily recorded during the test protocol. Once we reach optimal level of performance according to genetic makeup, the subsequent increment in performance depends upon various ergogenic methods to enhance the energy delivery system. ${ }^{3}$ An ergogenic aid by definition is a substance or device that enhances energy production, for use in competition or recovery ${ }^{4}$.

Of the various ergogenic methods available to achieve excellence, caffeine consumption has become increasingly popular. ${ }^{4}$ Caffeine is consumed by all of us \& it is one of the most widely used substances in the world. Every morning millions of people wake up to that morning cup of coffee that enables them to start their day. ${ }^{5}$ Many studies have reported an enhancement of prolonged submaximal exercise after caffeine ingestion. ${ }^{6}$. Caffeine affects almost every system in the body with the most effect on central nervous system. ${ }^{5}$ Caffeine acts as a central stimulant \& has effects on cognitive \& psychomotor functioning, particularly during mental \& physical fatigue and by enhancing alertness \& vigilance, it dampens pain perception, delays sleep . $6,7,8$

\section{Aims and Objectives}

1. To study the changes in the following (a) cardiovascular \& (b) respiratory parameters after 5 minutes of stationary cycling on bicycle ergometer, at a standardized power output in sedentary young male adults of age 18-26 years.

Systolic Blood Pressure (SBP), Diastolic Blood Pressure (DBP), Mean Arterial Pressure (MAP), Target Heart Rate (THR), Double Product of HR \& SBP, 1minute, 3 minute, 5minute post-exercise heart rate, Respiratory Rate (RR), Maximum Volume of oxygen consumption in each minute (VO2max).

2. To study the effect of caffeine $(6 \mathrm{mg} / \mathrm{kg}$ body weight) on above mentioned cardiovascular $\&$ respiratory parameters after 5 minutes of stationary cycling at a standardized power output in the same sedentary young male adults of age 18-26 years.

3. Comparison of above obtained results \& draw conclusions.

\section{Materials and Methods}

The study was conducted in the Department of Physiology in a tertiary hospital in city of Mumbai after approval by the ethics committee.

\section{Study Population}

75 normal, healthy, working male individuals of 18 26 years of age without peptic ulcer disease, bronchial asthma, tuberculosis or any major medical or surgical illness were randomly selected from a medical college in Mumbai.

\section{Criteria for Selection of Subjects}

\section{Inclusion Criteria}

- Age between 18-26 years.

- Male subjects.

- Healthy, working.

- Non-regular caffeine users (less than 2cups of coffee or equivalent /week).

- Non - athletes.

\section{Exclusion Criteria}

- Age less than 18 or more than 26 years.

- Obese individuals.

- Smokers.

- Alcoholics. 
- Regular caffeine users (ingesting $\geq 300 \mathrm{mg}$ caffeine / day).

- Performing more than 20 minutes of exercise on 3 or more / week.

- History of trauma.

- History of previous chronic disease.

Their nature of work in the entire day was basically a sedentary type. The subjects were first explained about the procedure of the test. Both verbal and written consents of the subjects were taken in their language. Detailed history of the subjects was taken regarding their diet, food preferences, personal habits, drug use or medication followed by detailed systemic examination of cardiovascular, respiratory, abdomen \& central nervous systems. They were divided into 2 groups. Control group (group A) comprised of 30 male adults. Study group (group B) consisted of 45 male participants. The participants were instructed to refrain from consuming caffeine for 48 hours prior to testing sessions as well as to avoid heavy exercise $\&$ alcohol for 24 hours prior $\&$ continue their routine.A list of food $\&$ beverages containing caffeine was provided to each participant in order to inform them of what products they should avoid. The control group was asked to exercise on the bicycle ergometer only during the first visit, they were not given caffeine for consumption. The study group were examined twice, once before caffeine consumption along with the control group and second time when they were given caffeine anhydrous powder in a dose of $6 \mathrm{mg} / \mathrm{kg}$ of body weight during their second visit. The subjects, both control group and study group were called in the morning after having light breakfast and were made to sit comfortably on a chair in a well - lit \& ventilated room at room temperature.

The following anthropometric parameters were studied

Age: was recorded from birthday by calendar to the nearest of year (<6months and $>6$ months)

Height: It was measured in $\mathrm{cm}$, with the help of height measurement stadiometer. The subjects were asked to stand erect, bare foot with head straight, feet together on the floor and the vertical distance from the ground to the vertex was measured.

Body Weight: It was measured in $\mathrm{kg}$, by portable human weighing machine.

Body mass index: Was calculated by the formula $\mathrm{BMI}=$ Weight (in $\mathrm{Kg}$ ) / Height (in m2)

Body fat percentage is measured by Bicycle Ergometer.

The subjects were then asked to perform exercise on bicycle Ergometer (Upright Bike 9380u ,Most Perfectly Ent Co. Ltd., Taiwan). The first session was to familiarise the participants and required them to complete a graded exercise protocol on a bicycle Ergometer in order to determine the power output required to elicit a THR, equating to55\% of individual age predicted maximum HR (220 - age).9 Once the THR is attained, the participant was instructed to continue to cycle at the power output, that equated to this HR value for a duration of 5 minutes. The subject pedalled the bicycle at the rate of 60 revolutions/minute. The rate was constant throughout exercise session. After 5 minutes of exercise session, following parameters were measured.

\section{Parameters Studied}

Systolic BP (SBP) in mm Hg, Diastolic BP (DBP) in $\mathrm{mm} \mathrm{Hg}$, Mean Arterial Pressure (MAP) in $\mathrm{mm}$ $\mathrm{Hg}: \mathrm{MAP}=1 / 3(\mathrm{SBP}-\mathrm{DBP})+\mathrm{DBP}$, Maximum heart rate in beats per minute (bpm), Target heart rate (THR) in beats per minute (bpm), Double product of HR \& SBP, also called MyocardialTension-Time (M.T.T.) which gives an index of myocardial oxygen consumption, Respiratory rate (RR) per minute, Maximum volume of oxygen consumption by body in each minute during exercise (VO2max) in $\mathrm{ml} / \mathrm{kg} / \mathrm{min}$ by the following formula VO2max $=111.33-(0.42 \times$ THR in bpm $)$. 10 At the end of 5 minutes (i.e. during recovery period ), their pulse rate was measured at three different times : at the end of 1 minute , 3 minutes, 5 minutes after the exercise was over. There was no significant difference in the above mentioned cardiorespiratory parameters in the control group and study group. 
After 2 days of first session only the study group (group B) participants were called for second time and were given caffeine anhydrous powder in a dose of $6 \mathrm{mg} / \mathrm{kg}$ of body weight \& instructed to ingest it with water in front of the investigator. After the rest period of 1hour, the exercise session as performed during the first visit was carried out. After 5 minutes of exercise session, above mentioned parameters were measured. The participants were not provided with any visual or verbal feedback regarding their work intensity.

\section{Observations}

Table 1 indicates the anthropometric parameters in control and participants. No significant difference was observed between the two groups for height, weight, BMI in both the age groups.

Table $2 \& 3$ illustrates mean values of cardiovascular parameters and Double product of heart rate and systolic blood pressure among study group male participants before and one hour after caffeine consumption with exercise. There is a statistical significant increase in all cardiovascular parameters, SBP (mm Hg), DBP (mm Hg), MAP (mm Hg), THR (bpm) and Double product of HR \& SBP after caffeine consumption

Table 4 shows the comparison of mean values of Respiratory parameters before and one hour after caffeine consumption with exercise among study group male participants. There is a significant increase in RR and significant decrease in VO2max after caffeine consumption.

Table 5 illustrates the mean values of 1 minute postexercise heart rate (PHR1), 3 minute post-exercise heart rate (PHR3), 5 minute post-exercise heart rate (PHR5) before and one hour after caffeine consumption with exercise among study group male participants. There is statistically significant increase in PHR1, PHR2, PHR3 in male participants after one hour of caffeine consumption with exercise.

\section{Results}

Table 1: Comparison of mean values of anthropometric parameters in male participants.

\begin{tabular}{|l|c|c|c|c|c|c|}
\hline \multirow{2}{*}{} & \multicolumn{2}{|c|}{$\begin{array}{c}\text { Study group } \\
(\mathrm{N}=45)\end{array}$} & \multicolumn{2}{c|}{$\begin{array}{c}\text { Control group } \\
(\mathrm{N}=30)\end{array}$} & $\begin{array}{c}\text { Unpai } \\
\text { red } \\
\text { t- test }\end{array}$ & $\begin{array}{c}\mathrm{P} \\
\text { value }\end{array}$ \\
\cline { 2 - 5 } & Mean & S.D. & Mean & S.D. & & 0.232 \\
\hline $\begin{array}{l}\text { Age } \\
\text { (years) }\end{array}$ & 19.58 & 1.733 & 20.58 & 3.872 & 1.213 & 0.018 \\
\hline $\begin{array}{l}\text { Weight } \\
(\mathrm{kg})\end{array}$ & 63.42 & 10.464 & 54.00 & 13.545 & 2.467 & 0.000 \\
\hline $\begin{array}{l}\text { Height } \\
(\mathrm{cm})\end{array}$ & 171.97 & 5.145 & 160.33 & 6.372 & 6.293 & 0.750 \\
\hline $\begin{array}{l}\text { BMI } \\
(\mathrm{kg} / \mathrm{m} 2)\end{array}$ & 21.35 & 3.172 & 20.95 & 5.078 & 0.320 & 0.023 \\
\hline $\begin{array}{l}\text { Body } \\
\text { Fat }(\%)\end{array}$ & 17.96 & 5.224 & 22.66 & 7.564 & 2.356 & 0.000 \\
\hline
\end{tabular}

Table 2: Comparison of mean values of cardiovascular parameters before and one hour after caffeine consumption with exercise among study group male participants

\begin{tabular}{|c|c|c|c|c|c|}
\hline \multicolumn{2}{|l|}{ Variable } & Mean & S. D. & Paired t- test & $\mathrm{P}$ value \\
\hline \multirow{2}{*}{$\begin{array}{l}\text { SBP }(\mathrm{mm} \\
\mathrm{Hg})\end{array}$} & Before & 136.00 & 9.21 & 5.024 & 0.000 \\
\hline & After & 150.00 & 9.61 & \multicolumn{2}{|c|}{ Difference is significant } \\
\hline \multirow{2}{*}{$\begin{array}{l}\text { DBP }(\mathrm{mm} \\
\mathrm{Hg})\end{array}$} & Before & 70.00 & 6.05 & 4.432 & 0.000 \\
\hline & After & 80.00 & 5.74 & \multicolumn{2}{|c|}{ Difference is significant } \\
\hline \multirow{2}{*}{$\begin{array}{l}\text { MAP } \\
(\mathrm{mm} \mathrm{Hg})\end{array}$} & Before & 93.49 & 4.67 & 11.697 & 0.000 \\
\hline & After & 102.87 & 3.93 & \multicolumn{2}{|c|}{ Difference is significant } \\
\hline \multirow{2}{*}{$\begin{array}{r}\text { THR } \\
(\mathrm{bpm})\end{array}$} & Before & 128.52 & 9.06 & 15.428 & 0.000 \\
\hline & After & 145.33 & 10.26 & \multicolumn{2}{|c|}{ Difference is significant } \\
\hline
\end{tabular}

Table 3: Comparison of mean values of Double product of heart rate and systolic blood pressure before and one hour after caffeine consumption with exercise among study group male participants

\begin{tabular}{|l|l|l|l|l|l|}
\hline \multicolumn{2}{|l|}{ Variable } & Mean & S. D. & Paired t- test & P value \\
\hline $\begin{array}{l}\text { Double product } \\
\text { of HR \& SBP }\end{array}$ & Before & $17,766.85$ & $2,119.39$ & 5.012 & 0.000 \\
\cline { 2 - 7 } & After & $22,292.79$ & $2,937.48$ & $\begin{array}{l}\text { Difference } \\
\text { significant }\end{array}$ & is \\
\hline
\end{tabular}

Table 4: Comparison of mean values of Respiratory parameters before and one hour after caffeine consumption with exercise among study group male participants

\begin{tabular}{|c|c|c|c|c|c|}
\hline \multicolumn{2}{|l|}{ Variable } & Mean & S. D. & $\begin{array}{c}\text { Paired t- } \\
\text { test }\end{array}$ & $P$ value \\
\hline \multirow[t]{2}{*}{$\mathrm{RR} \quad(/ \min )$} & Before & 28.00 & 4.85 & 5.067 & 0.000 \\
\hline & After & 34.00 & 4.11 & \multicolumn{2}{|c|}{ Difference is significant } \\
\hline \multirow{2}{*}{$\begin{array}{l}\text { VO2max } \\
(\mathrm{ml} / \mathrm{kg} / \mathrm{min})\end{array}$} & Before & 57.35 & 3.81 & 15.424 & 0.000 \\
\hline & After & 50.29 & 4.31 & \multicolumn{2}{|c|}{ Difference is significant } \\
\hline
\end{tabular}


Table 5: Comparison of mean values of 1 minute post-exercise heart rate (PHR1), 3 minute postexercise heart rate (PHR3), 5 minute post-exercise heart rate (PHR5) before and one hour after caffeine consumption with exercise among study groupmale participants

\begin{tabular}{|c|c|c|c|c|c|}
\hline \multicolumn{2}{|l|}{ Variable } & Mean & S. D. & $\begin{array}{c}\text { Paired t- } \\
\text { test }\end{array}$ & $P$ value \\
\hline \multirow{2}{*}{$\begin{array}{ll}\text { PHR } & 1 \\
\text { (bpm) }\end{array}$} & Before & 118.33 & 11.31 & 8.320 & 0.000 \\
\hline & After & 136.45 & 10.91 & \multicolumn{2}{|c|}{ Difference is significan } \\
\hline \multirow{2}{*}{$\begin{array}{l}\text { PHR } \\
\text { (bpm) }\end{array}$} & Before & 109.30 & 11.89 & 8.329 & 0.000 \\
\hline & After & 125.00 & 10.66 & \multicolumn{2}{|c|}{ Difference is significan } \\
\hline \multirow{2}{*}{$\begin{array}{l}\text { PHR } \\
\text { (bpm) }\end{array}$} & Before & 102.52 & 9.11 & 7650 & 0000 \\
\hline & After & 115.97 & 10.71 & \multicolumn{2}{|c|}{ Difference is significan } \\
\hline
\end{tabular}

\section{Discussion}

In the present study there was a statistically significant increase in all the cardiovascular parameters that is, Systolic Blood Pressure (SBP), Diastolic Blood Pressure (DBP), Mean Arterial Pressure (MAP), Target Heart Rate (THR), Double Product of HR \& SBP, after 5 minutes of stationary cycling on bicycle ergometer in normal young adults of age 18-26 years. Similar findings have been reported by various authors who studied the effect of caffeine on cardiopulmonary parameters. ${ }^{11}$, 12 On the contrary, Whitsett et al. ${ }^{13}$ found no differences in blood pressure and heart rate in either caffeine users or nonusers.

During a normal action potential the $\mathrm{Ca}+2$ entry through the $\mathrm{Ca}+2$ current (Ica) produces a small rise of $(\mathrm{Ca}+2) \mathrm{i}$ which thenactivates further release of $\mathrm{Ca}+2$ from $\mathrm{SR}$ i.e. $\mathrm{Ca}+2$-induced $\mathrm{Ca}+2$ release.' By analogy with this, the addition of caffeine will increase $\mathrm{SR} \mathrm{Ca}+2$ permeability and allow $\mathrm{Ca}+2$ ions to leave, thus increasing $(\mathrm{Ca}+2) \mathrm{i}$. This will then (via $\mathrm{Ca}+2$-induced $\mathrm{Ca}+2$ release) promote the release of more $\mathrm{Ca}+2$ from SR. 14 here exists several mechanisms which explain pressor effects of caffeine. Caffeine and other methylxanthines have been known to exert positive inotropic effect on cardiac muscle. This effect has been explained by various theories which includes, an increase in cyclic adenosine monophosphate levels via inhibition of phosphodiestrase, caffeine induced release of calcium from the sarcoplasmic reticulum, antagonism of endogenous adenosine receptors and thereby a progressive rise in vascular resistance and an increase in sympathetic activity. ${ }^{15}$

Double product of heart rate and systolic BP, also called as myocardial-tension-time index (M.T.T.I), gives an index of myocardial oxygen consumption. ${ }^{16,17,18}$ It is a relatively new and accepted index of left ventricular oxygen consumption and a substantial measure of the work load of the heart. There was statistically significant increase in double product in male participants after one hour of caffeine consumption with exercise, which may be due to increase in epinephrine and norepinephrine hormonal levels, increase in total peripheral resistance and/or an increase in stroke volume resulting in vasoconstriction and increased cardiac contractility.

Study of respiratory parameters revealed a statistically significant increase in respiratory rate (RR) after caffeine ingestion which may be due to stimulation of central nervous system (CNS) by methylxanthines which is known to augment the central inspiratory drive and increase chemoreceptor sensitivity to carbon dioxide. At the cellular level, xanthines block phosphodiesterases, therefore promoting cyclic adenosine monophosphate (AMP) accumulation. CNS is stimulated, with responses including (1) a regularized breathing pattern, (2) increased ventilatory drive, (3) increased chemoreceptor sensitivity to carbon dioxide. ${ }^{19}$

There was a significant decrease in VO2max in all the participants after one hour of caffeine consumption with exercise. Donrawee et al. ${ }^{20}$, Smile JS et. $\mathrm{Al}^{21}$, Nader et al ${ }^{22}$ in their studies have found significant increase in VO2max after 1 hour of caffeine consumption with submaximal exercise testing. ButMousavi A et al. found caffeine has no significant effect on maximal oxygen consumption (VO2max). ${ }^{23}$ The $\mathrm{O} 2$ delivery to the active muscles appears to be the limiting factor in muscle performance. VO2max varies with the level of physical conditioning. The responses of the cardiovascular system to regular exercise is to increase its capacity to deliver $\mathrm{O} 2$ to the active muscles and improve the ability of the muscle to use O2. Training progressively increases VO2max, 
which reaches a plateau at the highest level of conditioning. Physical conditioning is also associated with greater extraction of $\mathrm{O} 2$ from the blood by the muscles. With long-term training, capillary density in skeletal muscle increases. The number of mitochondria increases, as do the oxidative enzymes in mitochondria. In addition, levels of ATPase activity, myoglobin, and enzymes involved in lipid metabolism increase in response to physical conditioning. ${ }^{24}$

Though various studies have revealed increase in VO2 max after caffeine consumption which indicates caffeine to act as an ergogenic aid to enhance athletic performance, inhibit adenosine receptors and therefore increase skeletal muscle activity. However the decrease in VO2max 1 hour after caffeine consumption with exercise in our study indicates that caffeine during short term exercise in untrained individuals dosen't have an ergogenic effect on VO2 max. Thus caffeine does not appear to be ergogenic during short-term exercise. Training status may also pay a role in eliciting exercise performance benefits associated with caffeine ingestion. To date, the majority of studies that reported significant improvement in exercise performance following caffeine ingestion involved well-trained athletes, whereas the effect of caffeine may be different in a non-athletic population. It can be speculated that adaptive physiological changes that occur in trained athletes may result in greater responsiveness or sensitivity to caffeine uptake and its consequent effects. ${ }^{25}$

There was statistically significant increase in PHR1, PHR2, PHR 3 in male participants after one hour of caffeine consumption with exercise.

The increase in heart rate that accompanies exercise is considered to be due to the combination of parasympathetic withdrawal and sympathetic activation. The fall in heart rate immediately after exercise is considered to be a function of the reactivation of the parasympathetic nervous system. Recovery of heart rate immediately after exercise is a function of vagal reactivation. ${ }^{26}$

\section{Conclusion}

The present study shows that caffeine $(6 \mathrm{mg} / \mathrm{kg}$ body weight) ingestion prior to a short term exercise has an ergogenic effect by making appropriate changes in mentioned cardiovascular \& respiratory parameters in a normal young adults of age 18-26 years. The probable underlying mechanisms may be:

1. Caffeine exerts positive inotropic effect on cardiac muscle.

2. Caffeine causes increase in cyclic adenosine monophosphate levels via inhibitionof phosphodiestrase.

3. Caffeine causes release of calcium from the sarcoplasmic reticulum via $\mathrm{Ca}+2$-induced $\mathrm{Ca}+2$ release.

4. Antagonism of endogenous adenosine receptors.

5. Progressive rise in vascular resistance.

6. An increase in sympathetic activity causing increase in catecholamine hormonal levels.

7. At the cellular level caffeine blocks phosphodiesterases, promoting cyclic adenosine monophosphate (cAMP) accumulation thereby increasing ventilatory drive, increase in chemoreceptor sensitivity to carbon dioxide and this may be the cause for appropriate changes seen in respiratory parameters after caffeine consumption.

\section{Acknowledgement}

A special thanks to Dr Arun Chutani for compilation of data and statistical analysis.

\section{References}

1. Carl J.C., Kenneth E.P., Gregory M.C. Physical activity, exercise, and physical fitness: Definitions and distributions for healthrelated research. Public Health Reports March-April 1985; 100 (2): 126-131.

2. David E.Nielson, James D.George, Pat R. Vehrs, Ron L.Hager \& Carrie V. Ebb. Predicting VO2max in college - aged participants using Cycle Ergometery and Percieved functional ability. Measurement in 
Physical Education and Exercise science 2010; 14(4): 252-264.

3. Sharma Archana, Sandhu Jaspal. Effect of caffeine ingestion on strength and endurance performance of normal young adults. Doping Journal 2010; 7: 2.

4. The ergogenic effects of Caffeine Ephidrine and their combination on Exercise performance. Sports Nutrition Fall 2001.

5. Gregory R.Cox, Ben Desbrow, Paul G. Montgomery et al .Effect of different protocols of caffeine intake on metabolism and endurance performance. J Appl Physiol 2002; 92: 990 - 999.

6. Jacobson B.H. and Kulling F.A.Health and ergogenic effects of caffeine. Br.J.Sports Med; 23(1): 34-40.

7. Davis J.K. and Matt Green J. Caffeine and Anaerobic Performance - Ergogenic value and mechanisms of action. Sports Med 2009; 39(10): 813 - 832.

8. Hogervorst Eef, Bandelow Stephan, Jeroen Schmitt Stephan et al .Caffeine improves Physical and Cognitive Performance during Exhaustive Exercise. Med.Sci.Sports Exerc. 2008; 40 (10): 1841-1851.

9. Robergs A.Robert and Landwehr Roberto. The surprising history of the HRmax $=220$ - Agell Equation. Journal Of Exercise Physiology 2002; 5(2): 1-10.

10. Chaterjee Satipati, Chatterjee Pratima and Bandypadhyay Amit. Cardiorespiratory fitness of obese boys. Indian J Physiol Pharmacol. 2005; 49 (3): 353-357.

11. Lane D.James, Adcock R. Alison, Williams B. Redford et.al. Caffeine effects on cardiovascular and neuroendocrine responses to acute psychosocial stress and their relationship to level of habitual caffeine consumption. Psychosomatic Medicine 1990; 52: 320 - 336.

12. Pilli Raveendranadh, MUR Naidu, Pingali R.Usha et al. Study of Cardiovascular effects of caffeine in healthy human subjects, with special reference to pulse wave velocity using photoplethysmography. International Journal of Nutrition, Pharmacology, Neurological diseases September December 2012; 2 (3): 243 - 250.

13. van Dusseldrop $M$, Smits $P$, Thien $T$ and Katan M. B. Effect of decaffeinated versus regular coffee on blood pressure, A 12 week, double- blind trial. Hypertension 1989; 14: 563 - 569.

14. O`Neill S.C.and Eisner D.A. A mechanism for the effects of caffeine on $\mathrm{Ca} 2+$ release during diastole and systole in isolated rat ventricular myocytes. Journal of Physiology 1990; 430: 519 - 536.

15. Myers G.Martin. Effects of Caffeine on Blood Pressure. Arch Intern Med 1988; 148 :1189-1193.

16. Biswas A.Dalia and Kher R.Jayant. Cardiorespiratory changes associated with graded exercise and determination of aerobic power in male medical students $(18-19$ years). Indian J Physiol Pharmacol 1996; 40 (1): 79-82.

17. Smilee Johancy S, Nagaraja S, Ajay KT et al. Aerobic capacity in untrained young Indian men. Calicut Medical Journal 2008; 8 (2) : 3 .

18. Charansonney L.Olivier. Exercise testing in the 21st century: from an -old diagnostic to a novel health risk assessment tool.CardiologyOctober 25, 2012.

19. Gannon A.Barbara, RN, MS, FNP. Theophylline or Caffeine: which is best for apnea of prematurity? Neonatal network. Journal of Neonatal Nursing, December 2000; 19 (8): 33-36.

20. Donrawee Leelarungrayub, Maliwan sallepan and Sukanya Charoenwattana . Effects of acute caffinated coffee consumption on energy utilization related to glucose and lipid oxidation from short submaximal treadmill exercise in sedentary men. Nutrition and Metabolic Insights 2011; 4: $65-72$. 
21. Smilee Johancy S, Nagaraja S, Ajay KT et al. Aerobic capacity in untrained young Indian men. Calicut Medical Journal 2008 ; $8(2): 3$.

22. Rahnama Nader, Gaeini A.Abbas, Kazemi Fahimeh. The effectiveness of two energy drinks on selected indices of maximal cardiorespiratory fitness and blood lactate levels in male athletes. JRMS May \& June 2010; 15 (3): 127-132.

23. Mousavi A , Koushki Jahromi M , Salesi M , Daryanoush F, Khoshnam E, Nikseresht A , Hemati M . Impact of caffeine on heart rate and blood pressure at rest and during exercise. Journal of Jahrom University of Medical Sciences Spring 2011; 9 (1): 7-13.

24. Koppen BM, Stanton BA.Berne \& Levy Physiology. 2008; 6th edition: 409.

25. Wallman E.Karen, Goh W.Jin , Guelfi J.Kym . Effects of caffeine on exercise performance in sedentary females. Journal of Sports Science and Medicine 2010; 9: 183 189.

26. .Cole R.Christopher, Blackstone H.Euegene , Pashkow J.Fredrich, Claire E. et al . Heartrate recovery immediately after exercise as a predictor of mortality. The New England Journal of Medicine 1999; 341 (18) 13511357. 